\title{
BUSINESS CYCLES IN A DYNAMIC GENERAL EQUILIBRIUM MODEL WITH MONOPOLISTIC AND PERFECT COMPETITION
}

\section{Tam ve Tekelci Rekabet Üzerinden Dinamik Genel Denge Modelindeki İktisadi Dalgalanma}

Wei-Bin Zhang*

Geliş: 09.11.2019/ Kabul: 06.08.2020

DOI: $10.33399 /$ biibfad.644677

\begin{abstract}
The purpose of this study is to explain business cycles by developing a neoclassical growth model with perfect and monopolistic competition. The study generalizes the model by Zhang (2019) by making all the constant coefficients to be time dependent. The model determines income and wealth distribution on the basis of Walrasian general equilibrium theory, neoclassical growth theory, and Dixit-Stiglitz monopolistic competitive theory. The paper makes a unique contribution to the literature of economic growth with perfect and monopolistic competition by showing existence of business cycles due to exogenous shocks in the model with the economic mechanisms in the three main models of economic theory. The study shows how different shocks cause business cycles as argued by real business theory in macroeconomics.
\end{abstract}

Keywords: Business cycles; Solow growth model; periodic shocks; Dixit-Stiglitz model; monopolistic competition.

Jel Codes: C68; D41; D42.

\footnotetext{
* Prof. Ph.D., Ritsumeikan Asia Pacific University, Japan, wbz1@apu.ac.jp, ORCID: https:/ / orcid.org/0000-0002-3012-304X
} 
Öz

Bu çalışmanın amacı iktisadi dalgalanmayı tam ve tekelci rekabet üzerinden neoklasik bir büyüme modeli geliştirerek açıklamaktır. Çalışma Zhang (2019) tarafından oluşturulan modeli tüm sabit değişkenleri zamana bağımlı hale getirerek genelleştirmektedir. Model gelir ve servet dağılımını Walrasyan genel denge teorisi, neoklasik büyüme teorisi ve Dİxit-Stiglitz tekelci rekabet teorisi temeline göre belirlemektedir. Makale iktisadi dalgalanmanın varlığını modeldeki dışsal şoklara bağlı olarak ekonomik teorideki üç temel modeldeki mekanizmalar aracılığıyla göstererek tam ve tekelci rekabetle ekonomik büyüme literatürüne özgün bir katkı sağlamaktadır. Çalışma makroekonomideki reel iktisadi dalgalanma teorisinde savunulduğu gibi farklı şokların iktisadi dalgalanmaya nasıl yol açtığını göstermektedir.

Anahtar Kelimeler: İktisadi dalgalanma, solow büyüme modeli, dönemsel şoklar, dixit-stiglitz modeli, tekelci rekabet

Jel Kodlarn: C68; D41; D42.

\section{Introduction}

Modern economies are characterized by different types of consumers, different kinds of goods and services, and different market structures. Moreover, these different forces and their relations are changeable over time. How to properly model these complicated interactions in a single comprehensive framework with solid microeconomic foundation is obviously a challenging theoretical problem. Zhang $(2005,2008)$ has attempted to construct an analytical framework to examine various issues of economics in an integrated manner. This paper is another application of Zhang's alternative approach with the concept of disposable income and utility function to study business cycles caused by interdependence of economic mechanisms in some core models in economic theory. It introduces different periodic shocks to a generalized Zhang model to see how business cycles appear as emphasized in real business cycle theory.

This study generalizes the model by Zhang (2019) by making all the constant coefficients to be time dependent. Zhang builds a neoclassical growth model of heterogenous households with perfect and monopolistic competition. Dynamic general equilibrium is influenced 
by Walrasian general equilibrium theory (e.g., Walras, 1874; Arrow and Debreu, 1954; Arrow and Hahn, 1971; and Mas-Colell et al., 1995). Capital accumulation and final goods production with perfect competition are according to neoclassical growth theory (e.g., Solow, 1956; see also Burmeister and Dobell, 1970; and Zhang, 2008). Intermediate goods sector is modelled according to the Dixit-Stiglitz model with monopolistic competition (e.g., Dixit and Stiglitz, 1977; see also Krugman, 1979; Bertoletti and Etro, 2015; and Parenti, et.al., 2017). This paper is mainly concerned with demonstrating business cycles with different economic mechanisms. Different economic theories exist for explaining business cycles in the literature of economic dynamics (e.g., Zhang, 1991, 2006; Lorenz, 1993; Flaschel et al 1997; Chiarella and Flaschel, 2000). In macroeconomics courses, undergraduates are taught Keynesian business cycle theory (which emphasizes dynamics of monetary policies and monetary variables as causes) and real business cycle theory (which emphasizes real variable shocks as such technological changes as causes). However, there are only a few formal business cycles models built on microeconomic foundation. This paper makes a contribution to the literature of business cycles. Section 2 constructs the basic model of business cycles. Section 3 deals with properties of the dynamic model and plots the movement of the economy. Section 4 gives effects of various exogenous periodic shocks. Section 5 concludes the paper.

\section{The Model with Exogenous Time-Dependents Perturbations}

This section generalizes the neoclassical growth model of heterogeneous households with perfect competition and monopolistic competition proposed by Zhang (2019). The model is an integration Walrasian general theory, Solow's growth model (Solow, 1956) and model of monopolistic competition proposed by Dixit and Stiglitz (1977). The different approaches are integrated within a single framework by applying Zhang's concept of disposable income and utility function. As the model in this paper is only makes timeindependent parameters to be time-dependent, we define the model without much explaining the model in detail. 


\subsection{The total labor force}

The economy is composed by $J$ groups of people, indexed by, $\mathrm{j}=$ $1, \ldots, J$. People are 1 classified due to levels of human capital and preferences. Variables $T_{j}(t) \mathrm{T}(t)$ represent the work time of household $\mathrm{j}$. The total labor force and $(t)$ is given by:

$$
N(t)=\sum_{i=1}^{1} h_{j}(t) T_{j}(t) \bar{N}_{j}(t)
$$

In which $h_{j}(t)$ and $\bar{N}_{j}(t)$ are respectively the level of human capital and the population of group $j$. This paper treats $\bar{N}_{j}(t)$ and $h_{j}(t)$ as exogenous time-dependent coefficients.

\subsection{The final goods sector}

We use $(t), \tilde{N}(t)$ and $(t)$ to represent the capital input, labor input and output of the final goods sector. We use the Cobb-Douglas production function as follows:

$$
F(t)=A K^{\alpha(t)}(t) \tilde{N}^{\beta(t)}(t), 0<\alpha(t), \beta(t)<1, \alpha(t)+\beta(t)=1
$$

in which $A(t), \alpha(t)$ and $\beta(t)$ are time-dependent coefficients. Capital good is used as numeraire. Physical capital is depreciated at a rate $\delta_{k}(t)$. The wage rate $(t)$ and rate of interest $(t)$ are exogenously given to the sector. The profit of the final goods sector is:

$$
\pi_{0}(t)=F(t)-\left(r(t)+\delta_{k}(t)\right) K(t)-w(t) \tilde{N}(t) .
$$

The first-order conditions for maximization are:

$$
R(t)=\frac{\alpha(t) F(t)}{K(t)}, \quad w(t)=\frac{\beta(t) F(t)}{\widetilde{N}(t)}, \quad w_{j}(t)=h_{j}(t) w(t)
$$

in which $w_{j}(t)$ is the wage, rate of household $j$ and $R_{\delta}(t) \equiv r(t)+\delta_{k}(t)$. Equations (3) $w_{j}^{j}(t) w_{n}(t)=h_{j}(t) / h_{0 .}(t)$. This means that each worker is fairly paid on basis of the work efficiency.

\subsection{Profit distribution, current income and disposable income}

This paper uses the approach to describing behavior of households proposed by Zhang (1993). The concept of disposable income and utility function are applied to different economic problems in different 
fields of theoretical economics (see also, Zhang, 2005, 2008). Let $\bar{k}_{j}(t)$ denote group's household wealth. As in Zhang (2019), the total profit in the middle goods sector is equally shared between the households. Variable $\pi_{j(t)}$ denotes the profit shared by household $j$. The current income of household $j$ :

$$
y_{j}(t)=r(t) \bar{k}_{j}(t)+h_{j}(t) T_{j}(t) w(t)+\pi_{j}(t)
$$

Variable $\hat{y}_{j}(t)$ represents household $j$ 's disposable income. It is the current disposable income and the value of wealth:

$\hat{y}_{j}(t)=y_{j}(t)+\bar{k}_{j}(t)$

\subsection{Aggregating middle goods, Composite good for}

Household j distributes the disposable income between saving $s_{j}(t)$ , consuming final goods $d_{j}(t)$, and consuming middle goods $\widetilde{c}_{j}(\varepsilon, t)$. Variable $\widetilde{c}_{j}(\varepsilon, t)$ is the amount of variety $\varepsilon$ consumed by household $j$. Let variety $\varepsilon$ distribute within the range from 0 to,$\varepsilon \in[0, n]$. Following Dixit and Stiglitz (1977, see also Spence, 1976; and Tirole, 1988), we define composite good as follows:

$c_{j}(t)=\left(\int_{0}^{n(t)} \widetilde{c}_{j}^{\bar{\theta}(t)}(\varepsilon, t) d \varepsilon\right)^{1 / \bar{\theta}(t)}, \quad 1>\bar{\theta}_{j}(t)>0$

where $\bar{\theta}(t)$ is a positive parameter.

Let the price of $\widetilde{c}_{j}(\varepsilon, t)$ be denoted by $\widetilde{p}_{j}(\varepsilon, t)$. The disposable income is spent on saving, consuming final goods, and consuming middle goods. We have the budget constraint as follows:

$$
d_{j}(t)+\int_{0}^{n} \widetilde{p}_{j}(\varepsilon, t) \widetilde{c}_{j}(\varepsilon, t) d \varepsilon+s_{j}(t)=\hat{y}_{j}(t)
$$

We use $\bar{T}_{j}(t)$ to denote the leisure time and $T_{0}$ (fixed) available time for household $j$. The time constraint is expressed by:

$$
T_{j}(t)+\bar{T}_{j}(t)=T_{0}
$$

Inserting $T_{j}+\bar{T}_{j}=T_{0}$ in (4) yields:

$$
\hat{y}_{j}(t)=R(t) \bar{k}_{j}(t)-h_{j}(t) \bar{T}_{j}(t) w(t)+W_{j}(t)
$$


in which (5) is applied and

$R(t) \equiv 1+r(t), W_{j}(t) \equiv h_{j}(t) T_{0} w(t)+\pi_{j}(t)$

Substituting (8) into (7), we get:

$h_{j}(t) \bar{T}_{j}(t) w(t)+d_{j}(t)+\int_{0}^{n(t)} \tilde{p}(\varepsilon, t) \widetilde{c}_{j}(\varepsilon, t) d \varepsilon+s_{j}(t)=\bar{y}_{j}(t)$

in which

$\bar{y}_{j}(t)=R(t) \bar{k}_{j}(t)+W_{j}(t)$

\section{Utility functions and optimal behavior}

Utility function $U_{j}(t)$ is taken on the following form:

$$
\begin{aligned}
U_{j}(t)=T_{j}^{\sigma_{0 j}(t)} c_{j}^{\chi_{0 j}(t)}(t) d_{j}^{\xi_{0 j}(t)}(t) s_{j}^{\lambda_{0 j}(t)} \\
\sigma_{0 j}(t), \xi_{0 j}(t), \lambda_{0 j}(t), \chi_{0 j}(t)>0
\end{aligned}
$$

in which $\chi_{0 j}(t)$ is the propensity to consume intermediates, $\xi_{0 j}(t)$ is the propensity to consume final good, $\sigma_{0 j}(t)$ is the propensity to use leisure time, and $\lambda_{0 j}(t)$ is the propensity to save.

We use the two-stage method to analyze behavior of households (e.g., Dixit-Stiglitz, 1977; Chang, 2012). In the first stage, consider a price $(t)$ for $(t)$. The budget is then:

$h_{j}(t) w(t) \bar{T}_{j}(t) d_{j}(t)+p(t) c_{j}(t)+s_{j}(t)=\bar{y}_{j}(t)$

The optimal solution is expressed as:

$h_{j}(t) w(t) \bar{T}_{j}(t)=\sigma_{j}(t) \bar{y}_{j}(t), d_{j}(t)=\xi_{j}(t) \bar{y}_{j}(t), p(t) c_{j}(t)=\chi_{j}(t) \bar{y}_{j}(t)$, $s_{j}(t)=\lambda_{j}(t) \bar{y}_{j}(t)$

in which

$$
\begin{aligned}
& \sigma_{j}(t) \equiv p_{j}(t) \sigma_{0 j}(t), \quad \xi_{j}(t) \equiv p_{j}(t) \xi_{0 j}(t), \quad \chi_{j}(t) \equiv p_{j}(t) \chi_{0 j}(t), \\
& \lambda_{j}(t) \equiv p_{j}(t) \lambda_{0 j}(t), \quad p_{j}(t)=\frac{1}{\sigma_{0 j}(t)+\xi_{0 j}(t)+\chi_{0 j}(t)+\lambda_{0 j}(t)}
\end{aligned}
$$




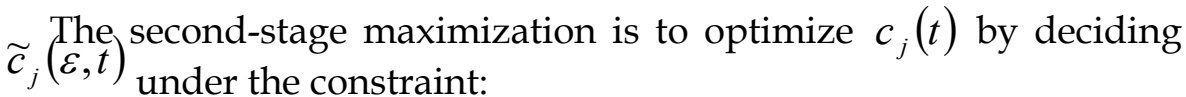

$\int_{0}^{n(t)} \tilde{p}(\varepsilon, t) \widetilde{c}_{j}(\varepsilon, t) d \varepsilon=p(t) c_{j}(t)$

The Langrangian function for the question is:

$L_{j}(t)=\left(\int_{0}^{n(t)} \widetilde{c}_{j}^{\theta(t)}(\varepsilon, t) d \varepsilon\right)^{1 / \bar{\theta}(t)}+h_{j}(t)\left\{p(t) c_{j}(t)-\int_{0}^{n(t)} \widetilde{p}(\varepsilon, t) \widetilde{c}_{j}(\varepsilon, t) d \varepsilon\right\}$

in which $h_{j}(t)$ is the Lagrangian multiplier. The first-order conditions are:

$$
\begin{aligned}
& \frac{\partial L_{j}(t)}{\partial \widetilde{c}_{j}(\varepsilon, t)}=c_{j}^{1-\bar{\theta}}(t) \widetilde{c}_{j}^{\bar{\theta}-1}(\varepsilon, t)-h_{j}(t) \widetilde{p}(\varepsilon, t)=0, \\
& \frac{\partial L_{j}(t)}{\partial h_{j}(t)}=p(t) c_{j}(t)-\int_{0}^{n} \tilde{p}(\varepsilon, t) \widetilde{c}_{j}(\varepsilon, t) d \varepsilon=0
\end{aligned}
$$

Equations (15) imply:

$c_{j}^{1-\bar{\theta}(t)}(t) \widetilde{c}_{j}^{\bar{\theta}(t)-1}(\varepsilon, t)=h_{j}(t) \widetilde{p}(\varepsilon, t)$

Equation (16) yields:

$$
\frac{\widetilde{c}_{j}(\varepsilon, t)}{\widetilde{c}_{j}(\mu, t)}=\left(\frac{\tilde{p}(\varepsilon, t)}{\widetilde{p}(\mu, t)}\right)^{1 /(\bar{\theta}(t)-1)}=\left(\frac{\tilde{p}(\varepsilon, t)}{\widetilde{p}(\mu, t)}\right)^{-\omega(t)}, \quad \bar{\theta}(t)=1-\frac{1}{\omega(t)}
$$

where $\omega_{j}(t) \omega j(t)$ is the elasticity of substitution between any two varieties:

$$
\frac{(\widetilde{p}(\varepsilon, t) / \widetilde{p}(\mu, t))}{\widetilde{c}_{j}(\varepsilon, t) / \widetilde{c}_{j}(\mu, t)} \frac{d\left(\widetilde{c_{j}}(\varepsilon, t) / \widetilde{c}_{j}(\mu, t)\right)}{d(\varepsilon, t) / \widetilde{p}(\mu, t))}=\omega(t)
$$

with (15) we also get:

$\widetilde{c}_{j}(\varepsilon, t) \widetilde{p}(\varepsilon, t)=\left(\frac{\widetilde{p}(\varepsilon, t)}{\widetilde{p}(\mu, t)}\right)^{\gamma(t)} \tilde{p}(\varepsilon, t) \widetilde{c}_{j}(\mu, t)$ 
in which $\gamma(t) \equiv 1 /(\bar{\theta}(t)-1)$ From the above equations, we get:

$p(t) c_{j}(t)=\chi_{j}(t) \gamma_{j}(t)=\int_{0}^{n(t)} \widetilde{p}(\varepsilon, t) \widetilde{c}_{j}(\varepsilon, t) d \varepsilon$

$\frac{\widetilde{c}_{j}(\gamma, t)}{\widetilde{p}^{\gamma(t)}(\gamma, t)} \int_{0}^{n(t)} \tilde{p}^{\bar{\theta}(t) \gamma(t)}(\varepsilon, t) d \varepsilon=\frac{\widetilde{c}_{j}(\gamma, t) P_{j}(t)}{\widetilde{p}^{\gamma(t)}(\gamma, t)}$

in which

$P_{j}(t) \equiv \int_{0}^{n} \tilde{p}^{\bar{\theta}(t) \gamma(t)}(\varepsilon, t) d \varepsilon$

We thus obtain:

$\widetilde{c}_{j}(\varepsilon, t)=\chi_{j}(t) \bar{\gamma}_{j}(t) \tilde{p}^{\gamma(t)}(\varepsilon, t) P_{j}^{-1}(t)$

From (19), we get

$$
p(t)=\frac{\chi_{j}(t) \bar{y}_{j}(t)}{c_{j}(t)}=\left(\int_{0}^{n(t)} \widetilde{c}_{j}^{\bar{\theta}(t)}(\varepsilon, t) d \varepsilon\right)^{-1 / \bar{\theta}(t)} \chi_{j}(t) \bar{y}_{j}(t)=P_{j}(t)^{-1 / \bar{\theta}(t) \gamma(t)}
$$

We calculate the value share of $\varepsilon$ in the total value of intermediates as:

$\varphi(\varepsilon, t)=\frac{\widetilde{p}(\varepsilon, t) \tilde{c}(\varepsilon, t)}{\bar{y}(t)}$

in which

$\bar{y}(t) \equiv \sum_{j=1}^{J} \bar{N}_{j}(t) \int_{0}^{n(t)} \tilde{p}(\varepsilon, t) \tilde{c}_{j}(\varepsilon, t) d \varepsilon, \quad \widetilde{c}(\varepsilon, t) \equiv \sum_{j=1}^{J} \widetilde{c}_{j}(\varepsilon, t) \bar{N}_{j}(t)$

\section{Accumulation of wealth}

Saving minus dissaving is the change in the household's wealth:

$\dot{k}_{j}(t)=s_{j}(t)-\bar{k}_{j}(t)$

\section{The middle goods sector}

Middle goods Markets are of monopolistic competition. There is no middle good which has an attribute very close to any given attribute of any other product. No firm considers possible impacts of its 
decisions on any other firm. Market equilibrium of demand and supply implies:

$$
\sum_{j=1}^{J} \widetilde{c}_{j}(\varepsilon, t) \bar{N}_{j}(t)=x(\varepsilon, t)
$$

where $x(\varepsilon, t)$ is the output level of variety $\varepsilon$. All the firms for meddle goods have the same cost 15 function. The labor force employed in production $l(\varepsilon, t)$ is linearly related to output:

$l(\varepsilon, t)=\widetilde{\alpha}(t)+\widetilde{\beta}(t) x(\varepsilon, t)$

where $\widetilde{\alpha}(t)$ is a fixed cost and $\widetilde{\beta}(t)$ is a positive parameter. The middle goods sector's total labor force $N_{x}(t)$ is:

$$
N_{x}(t)=\int_{0}^{n(t)} l(\varepsilon, t) d \varepsilon
$$

Producer $\varepsilon$ 's profit is:

$$
\bar{\pi}(\varepsilon, t)=\widetilde{p}(\varepsilon, t) x(\varepsilon, t)-(\widetilde{\alpha}(t)+\widetilde{\beta}(t) x(\varepsilon, t)) w(t)
$$

The symmetry means that all the firms in the sector produce the same quantity at the same price. We apply the shorthand notation: $x(t)=x_{j}(\varepsilon, t), \quad \pi(t)=\bar{\pi}(\varepsilon, t), \quad \tilde{p}(t)=\widetilde{p}(\varepsilon, t)$ for all $\varepsilon$.

With (23) and (26), we get:

$$
\bar{\pi}(t)=(\tilde{p}(t)-\widetilde{\beta} w(t)) \sum_{j=1}^{J} \widetilde{c}_{j}(\varepsilon, t) \bar{N}_{j}(t)-\widetilde{\alpha}(t) w(t)
$$

Inserting (19) in (28), we have

$$
\bar{\pi}(t)=(\tilde{p}(t)-\widetilde{\beta}(t) w(t)) \widetilde{p}^{\gamma(t)}(t) M(t)-\widetilde{\alpha}(t) w(t)
$$

in which

$$
M(t)=P_{j}^{-1}(t) \sum_{j=1}^{J} \chi_{j}(t) \bar{y}_{j}(t) \bar{N}_{j}(t)
$$


The first-order condition (i.e., $\partial \bar{\pi} / \partial \widetilde{p}=0$ ) leads to the fixedmarkup pricing rule:

$$
\tilde{p}(t)=\frac{\widetilde{\beta}(t) w(t)}{\bar{\theta}(t)}
$$

From (26) and (25), we get

$$
\bar{\pi}(t)=\vartheta(t) w^{1+\gamma(t)}(t) M(t)-\widetilde{\alpha}(t) w(t)
$$

in which

$$
\vartheta(t) \equiv\left(\frac{1}{\bar{\theta}(t)}-1\right) \widetilde{\beta}(t)\left(\frac{\widetilde{\beta}(t)}{\bar{\theta}(t)}\right)^{\gamma(t)}
$$

Each firm's action has negligible effect on $M(t)$. The profit share of household $\mathrm{j}$ is given by:

$$
\pi_{j}(t)=\frac{\mu_{j}(t) n(t) \bar{\pi}(t)}{\bar{N}_{j}(t)}
$$

where $n(t) \bar{\pi}(t)$ implies the total profit of the sector and share distribution is given as:

$$
\sum_{j=1}^{J} \mu_{j}(t)=1, \quad \mu_{j}(t) \geq 0
$$

\section{Demand and supply of final goods}

The output of the final good sector is equal to change in capital stock is plus the total consumption and depreciations of capital stock, we get:

$$
\dot{K}(t)=F(t)-\sum_{j=1}^{J} d_{J}(t) \bar{N}_{j}(t)-\delta_{k}(t) K(t)
$$

\section{The national wealth}

The national wealth $\bar{K}(t)$ is the sum of wealth values of all the households:

$$
\bar{K}(t)=\sum_{j=1}^{J} \bar{k}_{j}(t) \bar{N}_{j}
$$


We also have $K \bar{K}(t)=K(t)(t)=K(t)$.

\section{Input factors are fully employed}

The full employment of labor force implies:

$$
\tilde{N}(t)+N_{x}(t)=N(t)
$$

where $N_{x}(t)$ is the middle goods sector's labor force:

$$
N_{x}(t)=n(t) l(t)
$$

We developed the model. We now study properties and behavior of the economy.

\section{The Dynamic Properties of the Model}

We developed a growth model a growth model with integration of the Solow one-sector growth model, Walrasian general equilibrium theory, and the Dixit Stiglitz model. Before giving a computational procedure, we define:

$$
\begin{aligned}
& z(t) \equiv \frac{r(t)+\delta_{k}}{w(t)}, \\
& \left\{k_{j}(t)\right\} \equiv\left(k_{2}(t), \ldots, \bar{k}_{j}(t)\right)
\end{aligned}
$$

\section{Lemma}

The motion of the economy is given by the following differential equations:

$$
\begin{aligned}
& \dot{z}(t)=\phi_{1}\left(z(t),\left\{\bar{k}_{j}(t)\right\}, \bar{k}_{3}(t), t\right), \\
& \dot{\bar{k}}_{2}(t)=\phi_{2}\left(z(t), \bar{k}_{2}(t), \bar{k}_{3}(t), t\right), \\
& \dot{\bar{k}}_{3}(t)=\phi_{3}\left(z(t), \bar{k}_{2}(t), \bar{k}_{3}(t), t\right)
\end{aligned}
$$

where $\phi_{j}$ are functions of, $z(t)$ and $\left\{\bar{k}_{j}(t)\right\}$, and $t$, provided in the Appendix. The other variables are functions of $z(t)$ and $\left\{\bar{k}_{j}(t)\right\}$, and $t$, given by: $r(t)$ and $w(t)$ by $(A 3) \rightarrow \bar{k}_{1}(t)$ by $(A 18) \rightarrow \widetilde{p}(t)$ by $(30) \rightarrow \bar{y}_{j}(t)$ by $(A 8) \rightarrow \bar{T}_{j}(t), \quad d_{j}(t), \quad s_{j}(t) \quad$ by $\quad(12) \rightarrow K(t)$ by $(32) \rightarrow \widetilde{N}(t)$ by $\quad(A 1) \rightarrow \pi_{i}(t)$ by $\quad(A 6) \rightarrow x(t)$ by $(A 9) \rightarrow N_{x}(t)$ by 
$(A 9) \rightarrow N(t) 36$ by $(35) \rightarrow F(t)$ by $(A 2) \rightarrow c_{j}(t)$ by $(19) \rightarrow p(t)$ by $(20) \rightarrow l(t)$ by $(24) \rightarrow \varphi(t)$ by $(21) \rightarrow \bar{\pi}(t)$ by $(26) \rightarrow U_{j}(t)$ by $(10)$.

The Lemma is confirmed in the Appendix. Before conducting comparative dynamic analysis

with different exogenous periodic shocks, in the rest of this section we summarize the results in Zhang (2019) when all the parameters are invariant in time. The parameters are taken on the

following values:

$T_{0}=24, \quad \bar{\theta}=0.4, \quad \delta_{k}=0.05, \quad A=1.4, \quad n=200, \quad \alpha=0.35, \quad \bar{\alpha}=0.01$,

$\widetilde{\beta}=0.05, \quad \bar{N}_{1}=10, \quad \bar{N}_{2}=40, \quad \bar{N}_{3}=100, \quad h_{1}=4, \quad h_{2}=1.5, \quad h_{3}=1$,

$\mu_{1}=0.3, \quad \mu_{2}=0.3, \quad \mu_{3}=0.4, \quad \lambda_{01}=0.7, \quad \chi_{01}=0.1, \quad \xi_{01}=0.2, \quad \sigma_{01}=0.2$, $\xi_{03}=0.25, \quad \sigma_{03}=0.3$.

We specify the initial condition as follows:

$z_{1}(0)=0.07, \quad \vec{k}_{2}(0)=90, \quad \bar{k}_{2}(0)=46$

We plot the simulation result in Figure 1.

Figure 1: The Motion of the Economic System
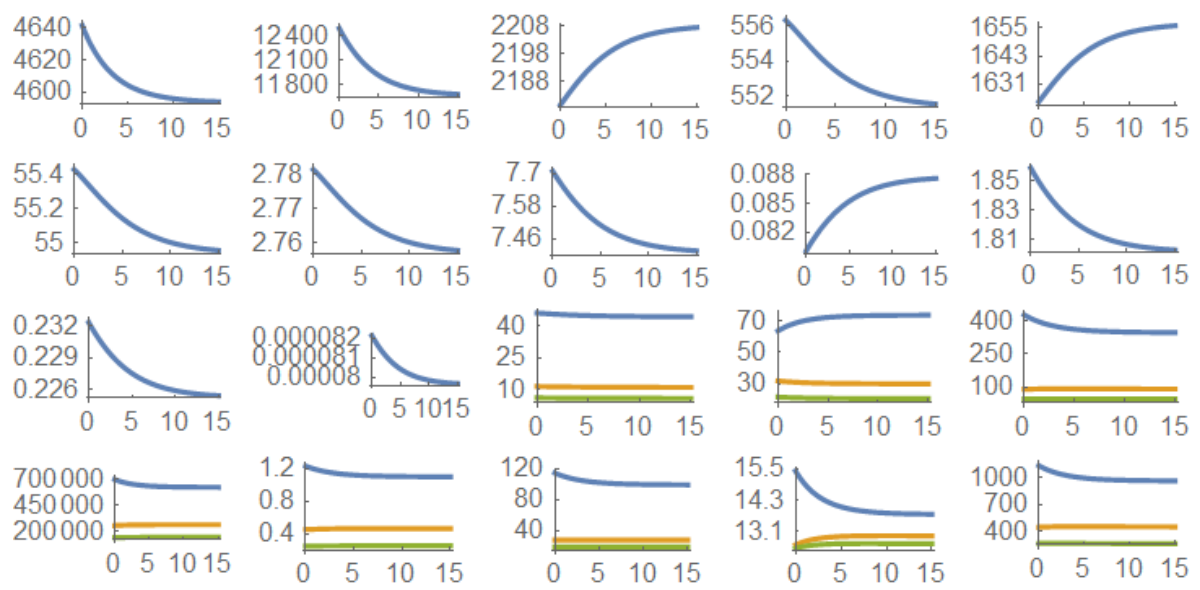

The values of the equilibrium point are calculated as follows: 
$F=4593, \quad K=11666, \quad N=2208, \quad N_{x}=551, \quad \tilde{N}=1657, \quad x=55, \quad l=2.76$, $\bar{\pi}=7.41, \quad r=0.088, \quad w=1.8, \quad \tilde{p}=0.23, \quad p=0.00008, \quad \pi_{1}=44.44$, $\pi_{2}=11.1, \quad \pi_{3}=5.93, \quad W_{1}=73.8, \quad W_{2}=29.9, \quad W_{3}=20.5, \quad \bar{k}_{1}=347, \quad \bar{k}_{2}=90.96$, $\bar{k}_{3}=45.6, \quad c_{1}=622588, \quad c_{2}=263598, \quad c_{3}=143082, \quad \tilde{c}_{1}=1.1$, $\tilde{c}_{2}=0.47, \quad \tilde{c}_{3}=0.25, \quad d_{1}=99, \quad d_{2}=28, \quad d_{3}=19, \quad \bar{T}_{1}=13.9, \quad \bar{T}_{2}=12.9$, $\bar{T}_{3}=12.6, \quad U_{1}=965, \quad U_{2}=450, U_{3}=262$

The eigenvalues are:

$-0.468,-0.395,-0.265$.

The stability guarantees validity of the following dynamic comparative analysis.

\section{Comparative Dynamic Analysis}

This section shows how various exogenous periodic shocks cause business cycles with reference to the growth path identified in the previous section. We use variable $\bar{\Delta} x(t)$ to stand for the 2 change rate of the variable $x(t)$ in percentage due to changes in value of a given parameter.

\subsection{Oscillations in the elasticity of substitution between two varieties rises}

We deal with the impact on the economy when the elasticity of substitution between two varieties is exogenously oscillated as follows: $\bar{\theta}(t)=0.4+0.02 \sin (t)$

Figure 2 shows the simulation result. We see that all the variables are periodic. The amplitudes of group 1's oscillations in the total income, wealth, and work hours are much larger than the other two groups'.

Figure 2: Oscillations in the Elasticity of Substitution between Two Varieties 


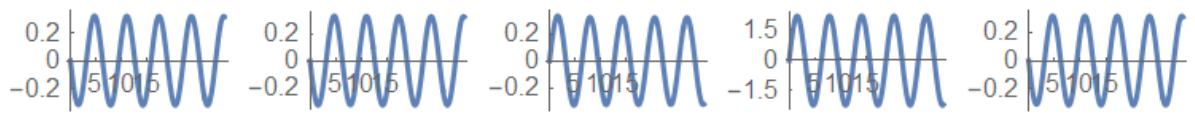
-15ACAPA . .

\subsection{Oscillations in the fixed labor cost of the middle goods firm}

We deal with the impact on the economy when the fixed labor cost of the middle goods firm isexogenously oscillated as follows:

$\widetilde{\alpha}(t)=0.01+0.01 \sin (t)$

Figure 3 shows the simulation result. As in real business cycle theory, changes in costs bring about business cycles. The amplitudes of group 1's oscillations in the total income, wealth, consumption of middle goods, and work hours are much larger than the other two groups'.

Figure 3: Oscillations in the Fixed Labor Cost of the Middle Goods
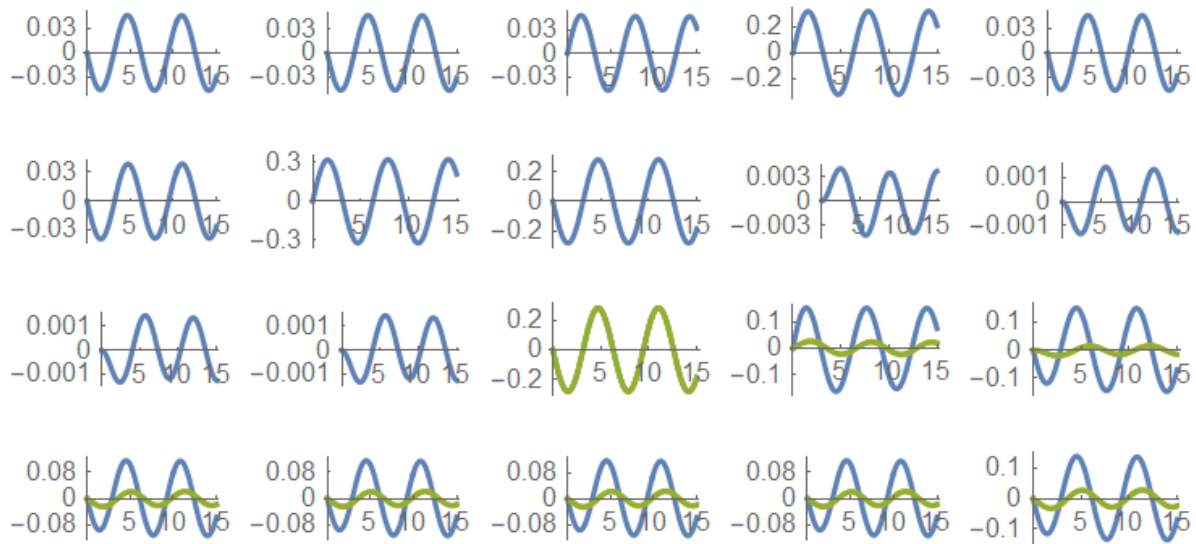


\subsection{Oscillations in the total factor productivity of the final goods sector}

We deal with the impact on the economy when the total factor productivity of the final goods sector is exogenously oscillated as follows:

$A(t)=1.4+0.1 \sin (t)$

Figure 4 shows the simulation result.

Figure 4: Oscillations in the Total Factor Productivity of the Final Goods Sector
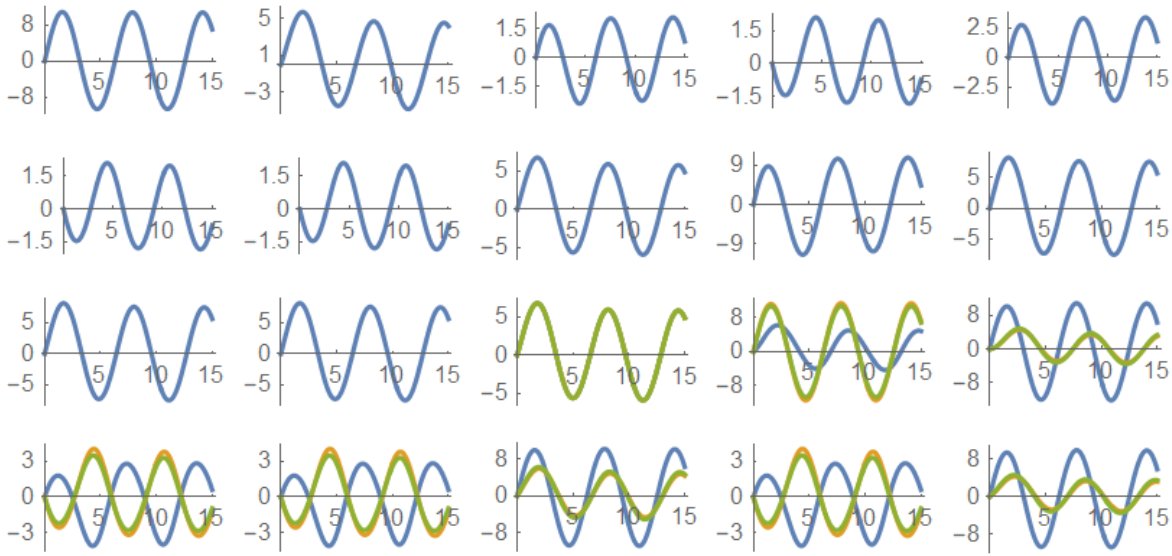

\subsection{Oscillations in group 1 's propensity to consume middle} goods

We deal with the impact on the economy when group 1's propensity to consume middle goods is exogenously oscillated as follows:

$\chi_{01}(t)=0.1+0.02 \sin (t)$

Figure 5 shows the simulation result. We see that group 1's preference oscillations have little impact on the other two groups' behavior. The macroeconomic variables and group 1's consumption, wealth and wage income have periodic changes. 
Figure 5: Oscillations in Group 1's Propensity to Consume Middle Goods
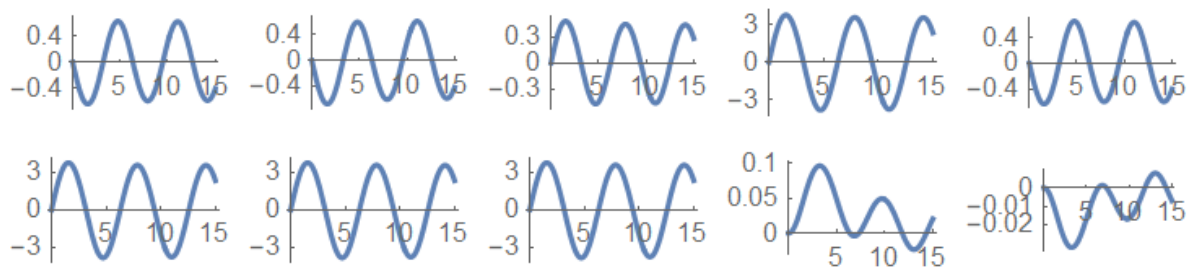

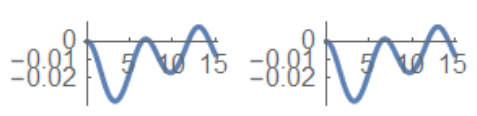
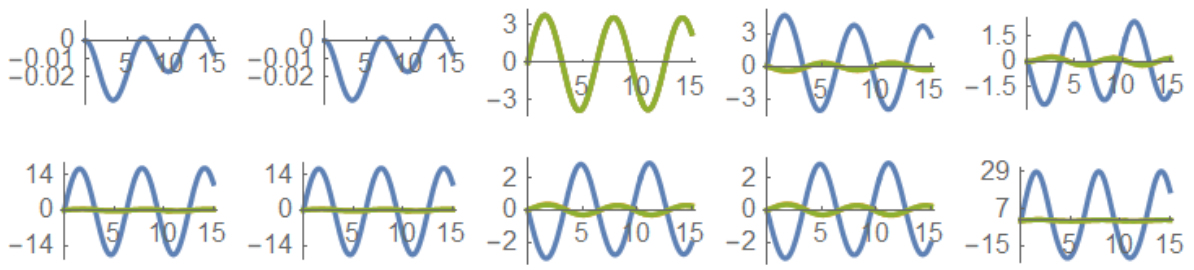

\subsection{Oscillations in group 1's propensity to save}

We deal with the impact on the economy when group 1's propensity to save on the economy is exogenously oscillated as follows:

$$
\lambda_{01}(t)=0.7+0.02 \sin (t)
$$

Figure 6 shows the simulation result. We see that group 1's preference oscillations have little impact on the other two groups' behavior. The macroeconomic variables and group 1's consumption, wealth and wage income have periodic changes.

Figure 6: Oscillations in Group 1's Propensity to Save
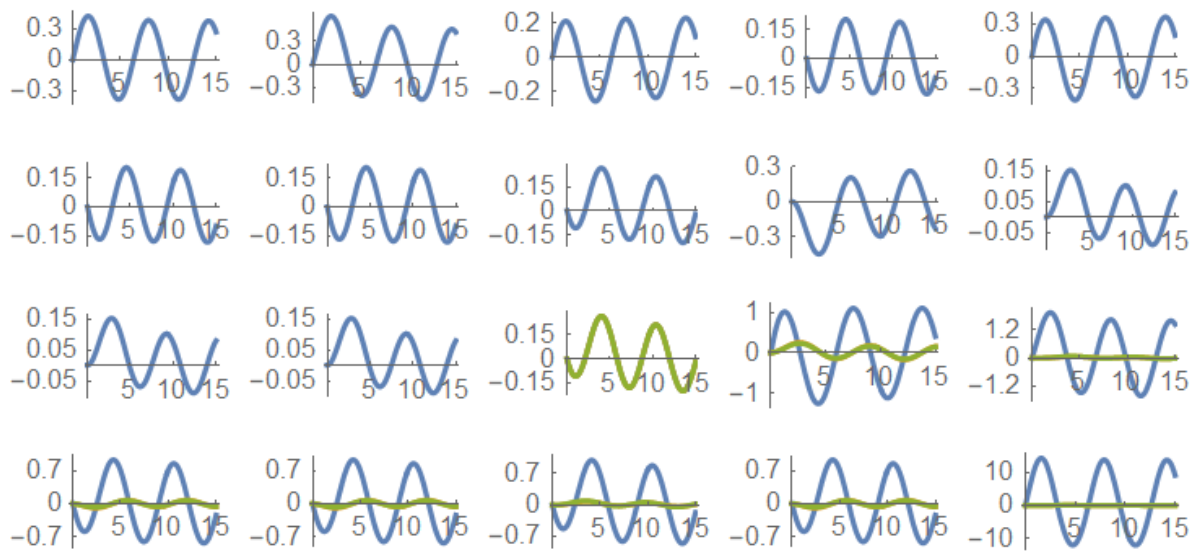


\subsection{Oscillations in group 3's human capital}

We deal with the impact on the economy when variety of middle goods is exogenously oscillated as follows:

$h_{3}(t)=1+0.2 \sin (t)$

Figure 7 shows the simulation result.

Figure 7: Oscillations in Group 3's Human Capital
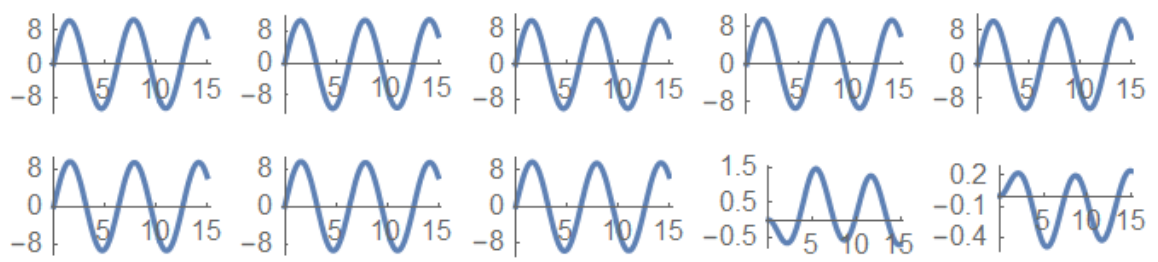

$\left.\begin{array}{r}0.2 \\ -0.4\end{array}\right] \sqrt[5]{10} 15$
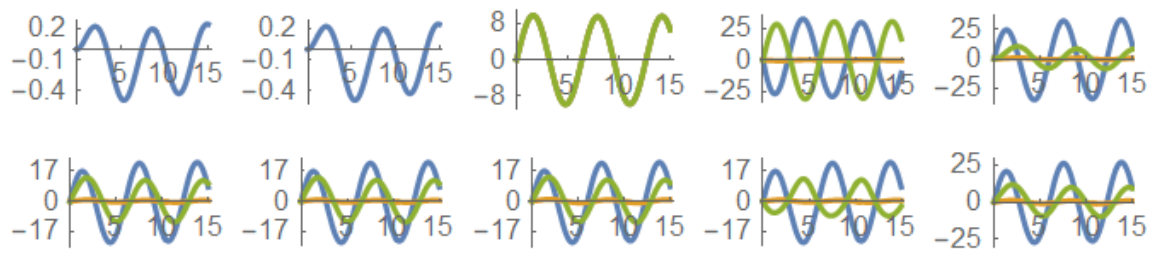

\subsection{Oscillations in group 3's population is increased}

We deal with the impact on the economy when group 3's population on the economy is exogenously oscillated as follows:

$\bar{N}_{3}(t)=100+10 \sin (t)$

Figure 8 shows the simulation result.

Figure 8: Oscillations in Group 3's Population

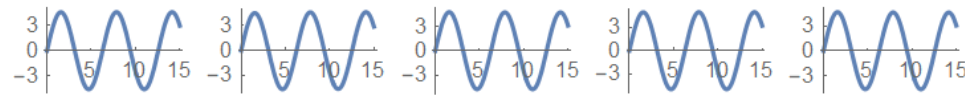

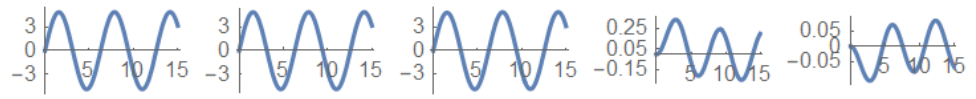

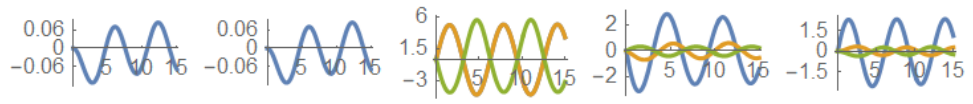

${ }_{-1.5}^{1.5} \mathrm{~A}$. 


\section{Concluding Remarks}

This paper generalized Zhang's model by making all the constant coefficients to be time dependent. The model determines income and wealth distribution on the basis of Walrasian general equilibrium theory, neoclassical growth theory, and Dixit-Stiglitz monopolistic competitive theory. It made a unique contribution to the literature of economic growth with perfect competition and monopolistic competition by showing existence of business cycles due to exogenous shocks in the integrated model. The model shows how different shocks generalized business cycles as argued by real business theory in macroeconomics. The model is quite general as it includes the basic economic mechanisms of the Solow-growth model, Walrasian general equilibrium theory, and Dixit-Stiglitz model. As there is a large amount of literature on generalizations and extensions of each of these models, it is not difficult to generalize our model on basis of the literature.

This paper generalized Zhang's model by making all the constant coefficients to be time dependent. The model determines income and wealth distribution on the basis of Walrasian general equilibrium theory, neoclassical growth theory, and Dixit-Stiglitz monopolistic competitive theory. It made a unique contribution to the literature of economic growth with perfect competition and monopolistic competition by showing existence of business cycles due to exogenous shocks in the integrated model. The model shows how different shocks generalized business cycles as argued by real business theory in macroeconomics. The model is quite general as it includes the basic economic mechanisms of the Solow-growth model, Walrasian general equilibrium theory, and Dixit-Stiglitz model. As there is a large amount of literature on generalizations and extensions of each of these models, it is not difficult to generalize our model on basis of the literature.

\section{Appendix: Proving the Lemma}

With (2) we obtain

$$
z \equiv \frac{r+\delta_{k}}{w}=\frac{\bar{\beta} \tilde{N}}{K}
$$


in which $\bar{\beta} \equiv \alpha / \beta$. With (2) and (A1), we get:

$F=A K\left(\frac{Z}{\bar{\beta}}\right)^{\beta}$

With (3), we get:

$r=\alpha A\left(\frac{Z}{\bar{\beta}}\right)-\delta_{k}, \quad w=\frac{r+\delta_{k}}{Z}$

Inserting (32) and (28) the concept of $\hat{y}_{j}$, we get

$\bar{y}_{j}=R k_{j}+h_{j} T_{0} w+\pi_{j}$

The definition of $M$ and $P_{j}=n \widetilde{p}^{\bar{\theta} \gamma}$ imply:

$M=\frac{1}{n \tilde{p}^{\bar{\theta} \gamma}} \sum_{j=1}^{J} \chi_{j} \vec{N}_{j} \bar{y}_{j}$

With (A5), (32) and (31), we get:

$\pi_{j}=\bar{\mu}_{j} \sum_{q=1}^{J} \chi_{q} \bar{N}_{q} \bar{y}_{q}-\frac{\mu_{j} \widetilde{\alpha} n w}{\bar{N}_{j}}$

where (30) is applied and

$\bar{\mu}_{j} \equiv \frac{\mu_{j} \vartheta}{(\widetilde{\beta} / \bar{\theta})^{\bar{\theta} \gamma} \bar{N}_{j}}$

Substituting (A6) into (A4) yields:

$\bar{y}_{j}-\bar{\mu}_{j} \sum_{q=1}^{J} \chi_{q} \bar{N}_{q} \bar{y}_{q}=R \bar{k}_{j}+\widetilde{\mu}_{j}$

in which

$\bar{\mu}_{j} \equiv\left(h_{j} T_{0}-\frac{\mu_{j} n \tilde{\alpha}}{\bar{N}_{j}}\right) w$

Equations (A7) are linear in $\bar{y}_{j}$ and $\bar{k}_{j}$. We get the solution of the linear equations as: 
$\bar{y}_{j}=\sum_{i=1}^{J} g_{i j}(z) \bar{k}_{i}+g_{0 j}(z)$

in which $g_{i j}(z)$ and $g_{0 j}(z)$ are related to $z$. With (24), we get:

$N_{x}=\widetilde{\alpha} n+\widetilde{\beta} n x$

With (19) and (23), we get:

$x=\sum_{j=1}^{J} \frac{\chi_{j} \bar{y}_{j} \bar{N}_{j}}{n \tilde{p}}$

Inserting (A10) in (A9), we get:

$N_{x}=\widetilde{\alpha} n+\widetilde{\beta} \sum_{j=1}^{J} \frac{\chi_{j} \bar{N}_{j} \bar{y}_{j}}{\widetilde{p}}$

With (A11) and (A1), we obtain:

$\frac{z K}{\bar{\beta}}+\widetilde{\alpha} n+\widetilde{\beta} \sum_{j=1}^{J} \frac{\chi_{j} \bar{N}_{j} \bar{y}_{j}}{\widetilde{p}}=N$

Inserting (34) in (A12), we have:

$\frac{z}{\bar{\beta}} \sum_{j=1}^{J} \bar{k}_{j} \bar{N}_{j}+\widetilde{\alpha} n+\widetilde{\beta} \sum_{j=1}^{J} \frac{\chi_{j} \bar{N}_{j} \bar{y}_{j}}{\widetilde{p}}=N$

From $T_{j}+\bar{T}_{j}=T_{0}$ and (1), we get:

$N=\widetilde{T}_{0}-\sum_{j=1}^{J} h_{j} \bar{N}_{j} \bar{T}_{j}$

in which

$\widetilde{T}_{0} \equiv \sum_{j=1}^{J} h_{j} T_{0} \bar{N}_{j}$

Inserting (12) in (A14), we obtain:

$N=\widetilde{T}_{0}-\frac{1}{w} \sum_{j=1}^{J} \bar{N}_{j} \sigma_{j} \bar{y}_{j}$

Inserting (A15) in (A13), we get: 
$\frac{z}{\bar{\beta}} \sum_{j=1}^{J} \bar{k}_{j} \bar{N}_{j}+\sum_{j=1}^{J} \bar{N}_{0 j} \bar{y}_{j}=\widetilde{T}_{0}-\widetilde{\alpha} n \quad(A 16)$

in which:

$\bar{N}_{0 j} \equiv\left(\frac{\chi_{j} \widetilde{\beta}}{\widetilde{p}}+\frac{\sigma_{j}}{w}\right) \bar{N}_{j}$

Inserting (A8) in (A16), we have:

$\sum_{j=1}^{J} \widetilde{g}_{j} \bar{k}_{j}=T_{0}-\widetilde{\alpha} n-g_{0}$

in which

$\widetilde{g}_{j} \equiv \frac{z \bar{N}_{j}}{\bar{\beta}}+g_{j}, \quad g_{j} \equiv \sum_{m=1}^{J} \bar{N}_{0 m} g_{j m}, \quad g_{0} \equiv \sum_{m=1}^{J} \bar{N}_{0 m} g_{0 m}$

Solving (A17) in $\bar{k}_{1}$, we obtain:

$\bar{k}_{1}\left(z,\left\{\bar{k}_{j}\right\}\right)=\left(T_{0}-\tilde{\alpha} n-g_{0}-\sum_{j=2}^{J} \widetilde{g}_{j} \bar{k}_{j}\right) \frac{1}{\widetilde{g}_{1}}$

In summary, all the variables are expressed as functions of $z$ and \{ $\left.\bar{k}_{j}\right\}$ by the procedure in the Lemma. By (22) and the procedure, we have

$\dot{\bar{k}}_{1}(t)=\phi_{0}\left(z(t),\left\{\bar{k}_{j}(t)\right\}, t\right) \equiv s_{1}(t)-\bar{k}_{1}(t)$
$\dot{\bar{k}}_{j}(t)=\phi_{j}\left(z(t),\left\{\bar{k}_{j}(t)\right\}, t\right) \equiv s_{j}(t)-\bar{k}_{j}(t)$

Taking derivatives of (A18) in time, we have:

$\dot{\bar{k}}_{1}=\frac{\partial \bar{k}_{1}}{\partial z} \dot{z}+\frac{\partial \bar{k}_{1}}{\partial t}+\sum_{j=2}^{J} \frac{\partial \bar{k}_{1}}{\partial \bar{k}_{j}} \dot{\bar{k}}_{j}$

By (A18)-(A21), we get:

$\dot{z}=\phi_{1}\left(z(t),\left\{\bar{k}_{j}(t)\right\}, t\right) \equiv\left(\phi_{0}-\frac{\partial \bar{k}_{k}}{\partial t}-\sum_{j=2}^{J} \frac{\partial \bar{k}_{1}}{\partial \bar{k}_{j}}\right)\left(\frac{\partial \bar{k}_{1}}{\partial z}\right)^{-1}$ 
By (A22) and (A20), we calculate the motion of $z(t)$ and $\left\{\bar{k}_{j}(t)\right\}$. The Lemma is confirmed.

\section{References}

Arrow K.J. and Debreu, G. (1954) Existence of an Equilibrium for a Competitive Economy. Econometrica, 22(3), 265-90.

Arrow, K.J. and Hahn, F.H. (1971) General Competitive Analysis. San Francisco: Holden-Day, Inc.

Bertoletti, P. and Etro, F. (2015) Monopolistic Competition When Income Matters. TheEconomic Journal, 127(603), 1217-43.

Burmeister, E. and Dobell, A.R. (1970) Mathematical Theories of Economic Growth. London:Collier Macmillan Publishers.

Chang, W.W. (2012) Monopolistic Competition and Product Diversity: Review and Extension. Journal of Economic Surveys, 26(5), 879910.

Chiarella, C. and Flaschel, P. (2000) The Dynamics of Keynesian Monetary Growth: Macro Foundations. Cambridge University Press, Cambridge.

Dixit, A. and Stiglitz, J.E. (1977) Monopolistic Competition and Optimum Product Diversity. American Economic Review, 67(3), 297-308.

Flaschel, P., Franke, R., and Semmler, W. (1997) Dynamic Macroeconomics. The MIT Press, Mass., Cambridge.

Krugman, P.R. (1979) A Model of Innovation, Technology Transfer, and the World Distribution of Income. Journal of Political Economy, 87(2), 253-66.

Lorenz, H.W. (1993) Nonlinear Dynamic Economics and Chaotic Motion. Springer-Verlag, Berlin.

Parenti, M., Ushchev, P., and Thisse, J.F. (2017) Toward a Theory of Monopolistic Competition. Journal of Economic Theory, 167(January), 86-115.

Solow, R. (1956) A Contribution to the Theory of Economic Growth. Quarterly Journal of Economics, 70(1), 65-94. 
Spence, M. (1976) Product Selection, Fixed Costs and Monopolistic Competition. Review of Economic Studies, 43(2), 217-35.

Tirole, J. (1988) The Theory of Industrial Organization. Cambridge: MIT Press.

Walras, L. (1874) Elements of Pure Economics, translated from the French by W. Jaffé, 1954. London: Allen and Unwin.

Waterson, M. (1984) Economic Theory of the Industry. Cambridge: Cambridge University Press.

Zhang, W.B. (1993) Woman's Labor Participation and Economic Growth - Creativity, Knowledge Utilization and Family Preference. Economics Letters, 42(1), 105-10.

Zhang, W.B. (2006) Discrete Dynamical Systems, Bifurcations and Chaos in Economics. Elsevier: Amsterdam.

Zhang, W.B. (1991) Synergetic Economics. Springer-Verlag, Heidelberg.

Zhang, W.B. (2005) Economic Growth Theory. Ashgate, London.

Zhang, W.B. (2008) International Trade Theory: Capital, Knowledge, Economic Structure, Money and Prices over Time and Space. Berlin: Springer.

Zhang, W.B. (2019) A Simple Growth Model Based on Neoclassical Growth, Monopolistic Competition, and Walrasian General Equilibrium Theories. International Journal of Academic Research in Business and Social Sciences 9(3), 1005-27. 
